Portland State University

PDXScholar

Chemistry Faculty Publications and

Presentations

Chemistry

$11-1-2012$

\title{
Progress toward red and near-infrared (NIR) emitting saccharide sensors
}

\author{
Martha Sibrian-Vazquez \\ Portland State University \\ Jorge O. Escobedo \\ Portland State University \\ Mark Lowry \\ Portland State University \\ Robert M. Strongin \\ Portland State University, strongin@pdx.edu
}

Follow this and additional works at: https://pdxscholar.library.pdx.edu/chem_fac

Part of the Analytical Chemistry Commons

Let us know how access to this document benefits you.

\section{Citation Details}

Sibrian.-Vazquez, M., Escobedo, J. O., Lowry, M., \& Strongin, R. M. (2012). Progress toward red and nearinfrared (NIR) emitting saccharide sensors. Pure \& Applied Chemistry, 84(11), 2443-2456.

This Article is brought to you for free and open access. It has been accepted for inclusion in Chemistry Faculty Publications and Presentations by an authorized administrator of PDXScholar. Please contact us if we can make this document more accessible: pdxscholar@pdx.edu. 
Pure Appl. Chem., Vol. 84, No. 11, pp. 2443-2456, 2012.

http://dx.doi.org/10.1351/PAC-CON-11-11-06

(C) 2012 IUPAC, Publication date (Web): 29 April 2012

\title{
Progress toward red and near-infrared (NIR) emitting saccharide sensors*
}

\author{
Martha Sibrian-Vazquez, Jorge O. Escobedo, Mark Lowry, and \\ Robert M. Strongin $¥$
}

Department of Chemistry, Portland State University, Portland, OR 97201, USA

\begin{abstract}
Red-shifted and near-infrared (NIR)-active rhodamine analogs and their boronic acid derivatives were synthesized and studied. These latter compounds function as fluorogenic NIR active substrates for sugar sensing. The effects of benzannulation and boronic acid functionalization on fluorophore optical and sensing properties are described.
\end{abstract}

Keywords: boronic acids; fluorescent indicators; naphthorhodamines; near infrared; seminaphthorhodamines; sugar sensing; xanthenes.

\section{INTRODUCTION}

During the past 15 years we have been interested in the design and synthesis of compounds with unique redox and chromophoric properties. The studies have included conjugated fullerene dimers [1], oligo$p$-phenylene rods [2], boronic acid-functionalized calix [4] resorcarenes [3], and, most recently, xanthene dyes [4]. Figure 1 shows some representative examples of these compounds.

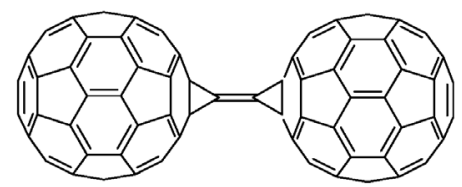

$\mathrm{C}_{122}$ A conjugated fullerene dimer<smiles>O=C([O-])c1ccccc1CNc1ccc2c(-c3ccccc3[18OH])c3ccc(=NCc4ccccc4Br)cc-3oc2c1</smiles>

RhoBo, a boronic acid derived xanthene from the rhodamines family

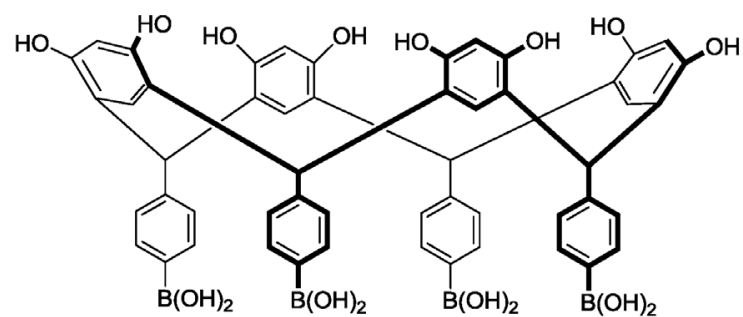

Crown isomer $\left(\mathrm{C}_{4 \mathrm{v}}\right)$ of tetraarylboronic acid resorcinarene, a boronic acid-functionalized calix[4]resorcarene

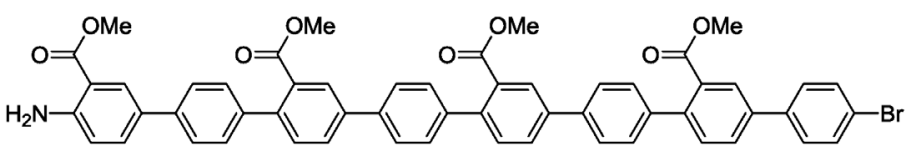

Functionalized oligo-p-phenylene consisting of 8 rings

Fig. 1 Representative compounds with unique redox and chromophoric properties.

*Pure Appl. Chem. 84, 2183-2498 (2012). A collection of invited papers based on presentations at the $14^{\text {th }}$ International Meeting on Boron Chemistry (IMEBORON-XIV), Niagara Falls, Canada, 11-15 September 2011.

¥Corresponding author 
Our interest in the xanthenes emanated from the discovery that resorcinarenes transform to xanthene chromophores upon standing (Fig. 2). Solutions containing the boronic acid resorcinarenes exhibited characteristic color changes in response to respective sugars [5]. The color formation of the resorcinarene solutions is due to ring opening followed by oxidation to form chromophores. Once the saccharide binds forming the boronate ester, and the boron (now more Lewis acidic) accepts an extra hydroxyl, a change in the ionization state of the hydroxyl groups in the fused-ring system takes place (Fig. 3) [6].

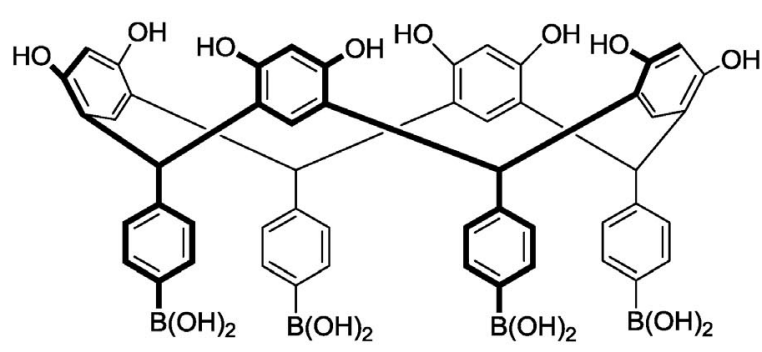

Fig. 2 Xanthene formation by oxidation of resorcinarenes.

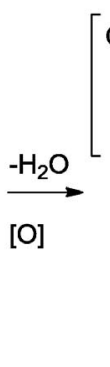

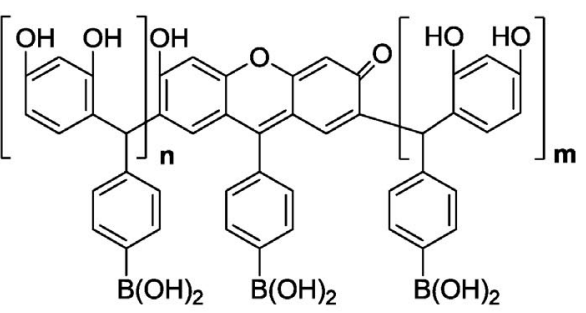

$\mathbf{n}=\mathbf{0}, \mathbf{1}, \mathbf{2}$, etc. $m=0,1,2$, etc.

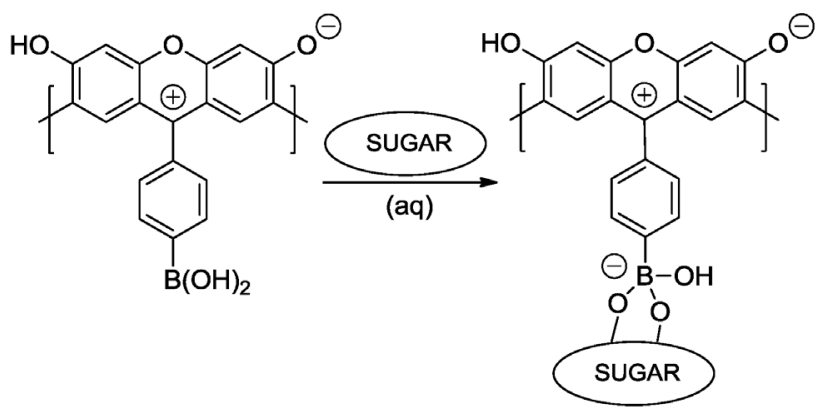

Fig. 3 Resonance forms of a resorcinarene-based xanthene during saccharide binding.

The detection of saccharides using boronic acid dyes typically has to be performed at elevated $\mathrm{pH}$, which may limit its application for studies at physiological conditions. We designed a rhodamine boronic acid (RhoBo) to overcome this limitation, inspired by Shinkai and James [7], since the presence of a nitrogen atom lowers the $\mathrm{p} K_{\mathrm{a}}$ of the boronic acid. The synthesis of the RhoBo has been optimized by using microwave technology [8]. We reported the high-performance liquid chromatography (HPLC) postcolumn detection of several saccharides (fructose, glucose, maltohexaose, maltotetraose, sialic acid, and GM1 brain ganglioside) [4] using RhoBo.

\section{TUNING CARBOHYDRATE SELECTIVITY}

RhoBo has proven to be a very versatile dye (Fig. 1). It is a unique boronic acid dye exhibiting tunable selectivity for ribose and derivatives over fructose [9]. The natural affinity of fructose for phenylboronic acid [10] is higher than that of ribose. However, intramolecular electrostatic interactions play a significant role in selectivity [9]. The mechanism of this change of selectivity of RhoBo for ribose and congeners compared to fructose is based in large part on tight binding interactions with the chromophore 
[11] (e.g., between the sugar hydroxyls and the xanthene carboxyl). Subsequently, others have used RhoBo for the selective recognition of engineered protein tetra-serine motifs in cells [12].

Once conditions for ribose selectivity were established, the selective detection of bioactive ribosecontaining molecules (Fig. 4) was achieved via a multidimensional method involving wavelength and time-based selectivity [8]. More recently, we have achieved detection of AICAr, a commercially available model for SAICAr [a biomarker of adenylosuccinate lyase (ADSL) deficiency, a rare but devastating inborn error of purine metabolism] in urine [13].

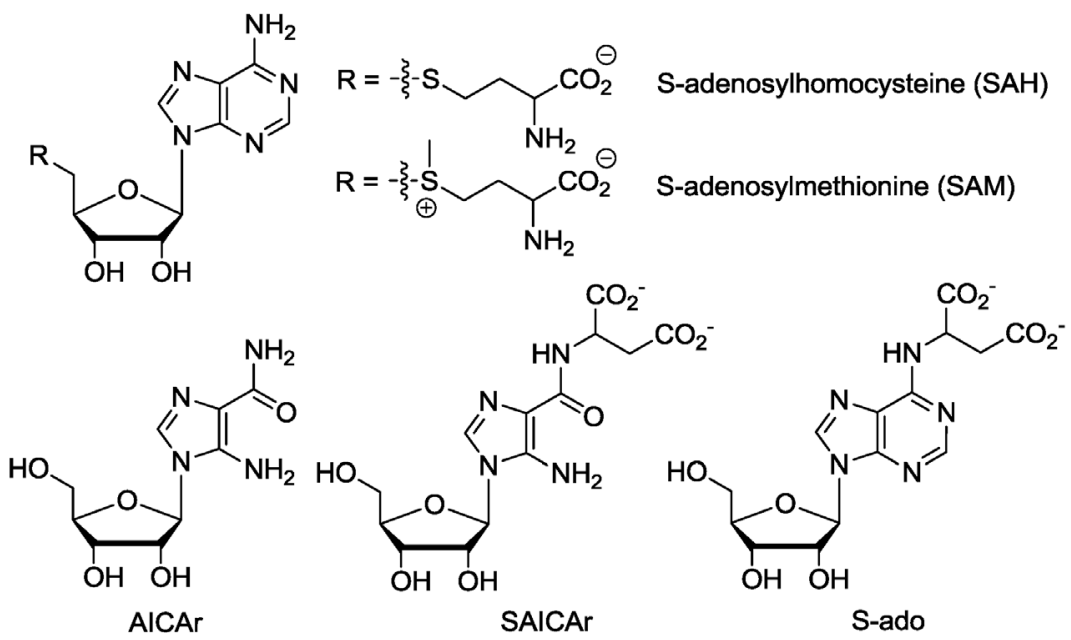

Fig. 4 Ribose-containing molecules of biomedical interest. SAM and SAH are indicators of oxidative stress, while the presence of SAICAr and S-ado in urine is linked to serious inborn errors of purine metabolism that cause autistic features, mental retardation, and neonatal seizures.

\section{LONG-WAVELENGTH ANALOGS}

Long-wavelength absorbing and emitting fluorophores are desirable in biodiagnostics. Xanthenes with red-shifted absorption and emission spectra have been pursued for some time. A well-known example includes a useful series of dual emission $\mathrm{pH}$ sensors with red emission based upon benzo[c]xanthene [14]. Seminaphthofluoresceins (SNAFLs) and seminaphthorhodafluors (SNARFs) are type [c] annulated probes with ionizable moieties at positions 3 and 10. They are represented in Fig. 5 as compounds type [c], I. For SNAFLs X = Y = oxygen; whereas SNARFs were substituted at the 10-position with nitrogen. We recently reported a series of seminaphthofluorones including type [a] and [b] annulations (i.e. type [a], I and type [b], I with annulations "down" and "linear" with respect to the known type [c], I compounds) [15]. Also included in the series as a design variable was the transposition of the ionizable moieties (compounds types [a], [b], and [c], II). This design variable was found to have a significant effect on dye properties comparable to that of the direction of annulation. This series included members with unusually large Stokes shifts $(\sim 200 \mathrm{~nm})$ and emissions well into the near infrared (NIR) (>750 $\mathrm{nm}$ in aqueous solutions and approaching $790 \mathrm{~nm}$ in dimethyl sulfoxide, DMSO). While these classes of compounds have many desirable properties, there are occasions when insensitivity to changes in $\mathrm{pH}$ would be desirable. Rhodamine analogs would provide this attribute, yet to the best of our knowledge, there have been no reported semi-annulated rhodamine analogs in which $\mathrm{X}=\mathrm{Y}=$ nitrogen based on any of these scaffolds. 
<smiles></smiles>

Type [c], I<smiles></smiles>

Type [c], II<smiles></smiles>

Type [b], I<smiles>[Y]c1ccc2cc3c([R])c4ccc([Y])cc4cc3cc2c1</smiles>

Type [b], II<smiles></smiles>

Type [a], I<smiles>[Y]c1ccc2c(c1)oc1c(C)cc3ccc([Y])cc3c12</smiles>

Type [a], II

Fig. 5 Benzoxanthene frameworks. $\mathrm{X}, \mathrm{Y}=\mathrm{N}$ or $\mathrm{O}$.

Herein, we report the synthesis of the first member in this semiannulated rhodamine family, an asymmetric type [c] seminapthorhodamine analog (1) with red-shifted emission compared to the rhodamine 110 precursor used for the original RhoBo. In addition, a bis-boronic acid (2) based on this new rhodamine has been synthesized. This new compound is an indicator with differing geometry and putative tight binding with saccharides as compared to RhoBo. It should be useful for applications with samples showing background absorbance well beyond $500 \mathrm{~nm}$.

Annulation of a second fused ring to the chromophore has also been used to further increase the wavelength of maximum absorption and emission. Examples include Vita Blue [16] and the commercially available naphthofluorescein. A naphthorhodamine-based reduction-triggered red fluorescent<smiles></smiles>

1<smiles>Nc1ccc2c(ccc3c(-c4ccccc4C(=O)[O-])c4ccc5cc(=[NH2+])ccc5c4oc32)c1</smiles>

3<smiles>O=[N+]([O-])c1ccccc1-c1c2ccc(=NCc3ccccc3B(O)O)cc-2oc2c1ccc1cc(NCc3ccccc3B(O)O)ccc12</smiles>

2<smiles>O=C([O-])c1ccccc1-c1c2ccc3cc(NCc4ccccc4B(O)O)ccc3c2oc2c1ccc1cc(=NCc3ccccc3B(O)O)ccc12</smiles>

4

Fig. 6 Structures of rhodamine bis-boronic acids and their corresponding precursors. 
probe for the detection of oligonucleotide sequences has been recently reported [17]. Herein we also report the synthesis of a naphthorhodamine (3) and its corresponding long-wavelength bis-boronic acid (4). This indicator displays absorption and excitation beyond $600 \mathrm{~nm}$ and embodies yet another sensing scaffold that will be well suited for sensing larger analytes including disaccharides. The two new rhodamine bis-boronic acids are thus analogs of the original RhoBo with increases in the number of fused rings in the chromophore affording red-shifted absorptions and emission maxima approaching the NIR (see Table 1 and Figs. 6 and 7). The absorption and emission of bis-boronic acid $\mathbf{4}$ is further shifted deeper into the red and NIR upon the binding of sugars.

Table 1 Spectral properties of rhodamine bis-boronic acids and their respective precursors.

\begin{tabular}{lllcc}
\hline Compound & Abs $\left(\varepsilon, \mathrm{M}^{-1} \mathrm{~cm}^{-1}\right)$ & Ex/Em (Q.Y.) & Brightness & $\begin{array}{c}\text { DMSO:buffer } \\
\text { ratio }^{\mathrm{a}}\end{array}$ \\
\hline Rhodamine $110^{\mathrm{b}}$ & $495(66800 @ 492)$ & $\mathrm{NA} / 523(0.91)$ & $60788 @ 492$ & NA \\
RhoBo & $501(22149)$ & $502 / 528(0.30)^{\mathrm{c}, \mathrm{f}}$ & 6645 & $1: 9$ \\
$\mathbf{1}$ & $535(42701)$ & $534 / 628(0.19)$ & 8083 & $1: 9$ \\
Bis-boronic acid 2 & $560(20326)$ & $568 / 638(0.15)^{\mathrm{e}}$ & $3032^{\mathrm{e}}$ & $1: 9$ \\
$\mathbf{3}$ & $578(11994)^{\mathrm{d}}$ & $584 / 668(0.10)$ & $1144^{\mathrm{d}}$ & $1: 9$ \\
Bis-boronic acid 4 & $628(10759)^{\mathrm{d}}$ & $612 / 692(0.004)^{\mathrm{f}}$ & $43^{\mathrm{d}, \mathrm{f}}$ & $1: 9$ \\
Rhodamine 110 & $503(67905)$ & $502 / 526(\mathrm{NA})$ & $\mathrm{NA}$ & $1: 1$ \\
RhoBo & $504(21003)$ & $504 / 528(\mathrm{NA})$ & $\mathrm{NA}$ & $1: 1$ \\
$\mathbf{1}$ & $542(21064)$ & $542 / 630(0.30)$ & 6298 & $1: 1$ \\
Bis-boronic acid 2 & $579(23096)$ & $580 / 643(0.35)$ & 8037 & $1: 1$ \\
$\mathbf{3}$ & $602(1081)^{\mathrm{g}}$ & $596 / 676(0.11)$ & $292^{\mathrm{g}}$ & $1: 1$ \\
Bis-boronic acid 4 & $616(1616)^{\mathrm{g}}$ & $624 / 700(0.18)$ & & $1: 1$ \\
\hline
\end{tabular}

${ }^{\mathrm{a}}$ Final $\mathrm{pH} 7.4$ phosphate buffer concentration was $12.5 \mathrm{mM}$.

bSolvent was $10 \mathrm{mM}$ HEPES, pH 7.5, $15 \%$ (v/v) EtOH; values taken from ref. [19].

cValue taken from ref. [12] .

dPartial lactone formation.

eWeak PET quenching.

${ }^{\mathrm{f}}$ Strong PET quenching.

gNear complete lactone formation.

\section{SYNTHESIS OF BIS-BORONIC ACIDS AND PRECURSORS}

\section{Synthesis of seminaphthorhodamine bis-boronic acid 2}

The starting material, 2-(4-amino-2-hydroxybenzoyl)benzoic acid, was obtained via the basic hydrolysis of rhodamine 110 at $160{ }^{\circ} \mathrm{C}$ over $3 \mathrm{~h}$ in $92 \%$ yield. Acid condensation with 1,6-aminohydroxynaphthalene using a 1:1 mixture of $\mathrm{CH}_{3} \mathrm{SO}_{3} \mathrm{H}$ :TFA afforded the corresponding seminaphthorhodamine 1 in $63 \%$ yield after isolation by flash column chromatography with $\mathrm{CH}_{2} \mathrm{Cl}_{2}: \mathrm{MeOH}, 9: 1$. Reductive amination to produce the corresponding bis-boronic acid $\mathbf{2}$ was carried out in dichloroethane (DCE) in two steps. Other solvents including MeCN and tetrahydrofuran (THF) were also used, but gave low yields (less than $1 \%$ ) of the desired target. The first step involved the reaction of 1 with 2 -formylboronic acid and triacetoxy sodium borohydride under microwave irradiation at $130{ }^{\circ} \mathrm{C}$ for $40 \mathrm{~min}$. The microwave vial was opened, and acetic acid was added in one portion and the mixture heated for an additional $40 \mathrm{~min}$ at $130{ }^{\circ} \mathrm{C}$. The mixture is neutralized with saturated $\mathrm{NaHCO}_{3}$ and the target compound isolated by preparative thin-layer chromatography (TLC) using $\mathrm{CH}_{2} \mathrm{Cl}_{2}: \mathrm{MeOH}$ 9:1. The target compound was characterized by ${ }^{1} \mathrm{H}$ NMR, high-resolution electrospray ionization mass spectometry (HR-ESI-MS), and its purity (96\%) was determined by reversed-phase HPLC (Scheme 1). 
<smiles>N=c1ccc2c(-c3ccccc3[N+](=O)[O-])c3ccc(N)cc3oc-2c1</smiles>

rhodamine 110<smiles>Nc1ccc(C(=O)c2ccccc2C(=O)O)c(O)c1</smiles>

2-(4-amino-2-hydroxybenzoyl) benzoic acid

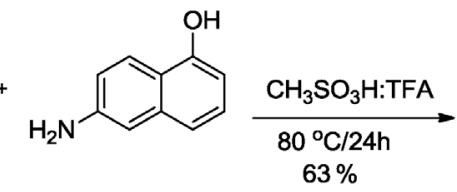

$63 \%$<smiles></smiles>

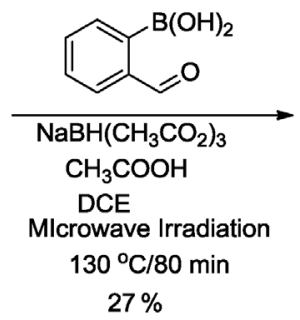

$27 \%$<smiles></smiles>

2

Scheme 1 Synthesis of seminaphthorhodamine bis-boronic acid 2.

\section{Synthesis of naphthorhodamine bis-boronic acid 4}

Naphthorhodamine 3 was synthesized in $74 \%$ yield by the acid-promoted condensation of phthalic anhydride and 1,6-aminohydroxynaphthalene via heating in the presence of trifluoromethane sulfonic acid at $100{ }^{\circ} \mathrm{C}$ for $2 \mathrm{~h}$, then at $140{ }^{\circ} \mathrm{C}$ for an additional $2 \mathrm{~h}$ under Ar. Reductive amination to produce the corresponding bis-boronic acid $\mathbf{4}$ was carried out in DCE in two steps as described above. Optimal reaction conditions were obtained by monitoring the reaction by reversed-phase HPLC. The target compound was isolated in $38 \%$ yield by preparative TLC using $\mathrm{CH}_{2} \mathrm{Cl}_{2}: \mathrm{MeOH}$ 95:5 for elution. Naphthorhodamine 3 and the target compound were characterized by ${ }^{1} \mathrm{H}$ NMR, HR-ESI-MS, and their

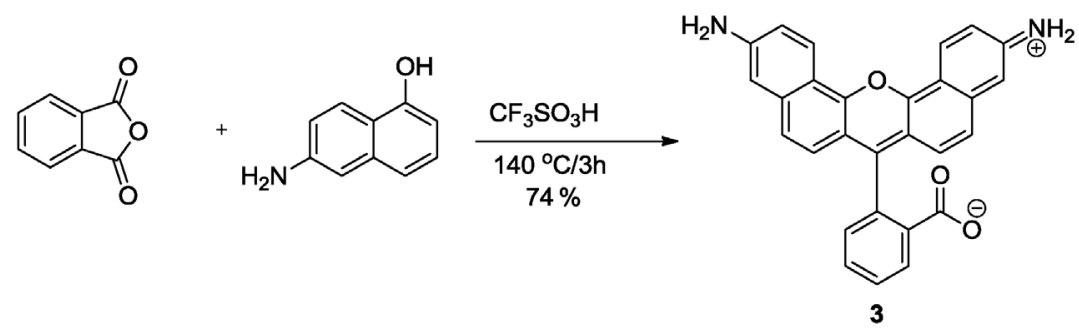
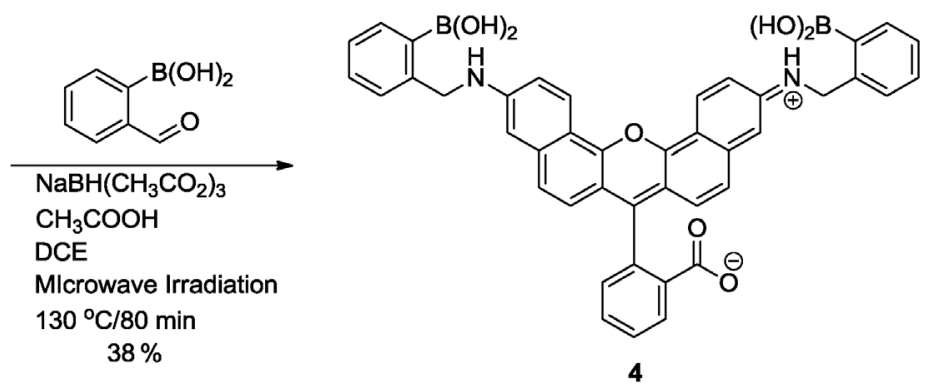

Scheme 2 Synthesis of naphthorhodamine bis-boronic acid 4. 
purity ( $99 \%$ and $95 \%$, respectively) was determined by reversed-phase HPLC on a $\mathrm{C}_{18}$ reversed-phase column and a gradient solvent system composed of $\mathrm{H}_{2} \mathrm{O}: 1 \%$ TFA in MeCN for elution (Scheme 2).

\section{SPECTRAL PROPERTIES}

Annulation led to an increase in absorption and emission wavelengths as expected. Figure 7 shows the spectral behavior of DMSO:buffer solutions of rhodamine bis-boronic acids and their respective pre-
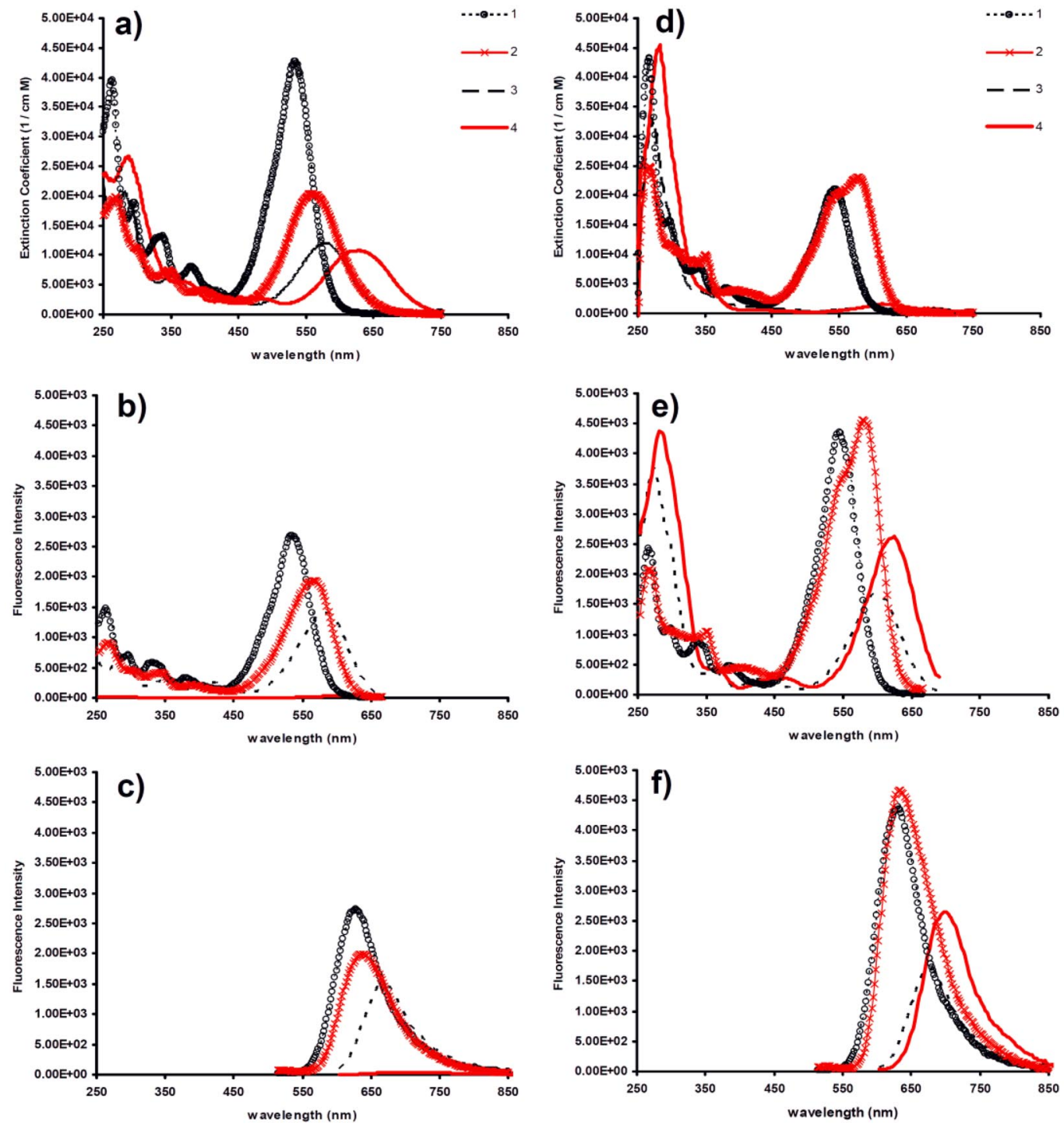

Fig. 7 Absorption and fluorescence spectra of solutions of rhodamine bis-boronic acids and their respective precursors. (a-c) Compounds 1-4 in DMSO:buffer 1:9. (d-f) Compounds 1-4 in DMSO:buffer 1:1. Emission and excitation spectra for $1(2.25 \mu \mathrm{M})$ and bis-boronic acid $2(3.75 \mu \mathrm{M})$ were excited and monitored at 500 and $675 \mathrm{~nm}$. Emission and excitation spectra for $3(12.5 \mu \mathrm{M})$ and bis-boronic acid $4(7.5 \mu \mathrm{M})$ were excited and monitored at 590 and $700 \mathrm{~nm}$. Excitation and emission spectra are normalized to their absorbance at the excitation wavelength and are proportional to quantum yield. 
cursors. Table 1 summarizes the spectral properties of rhodamine bis-boronic acids and their precursors. The seminapthorhodamine 1 maximum absorption in DMSO buffer 1:9 is at $535 \mathrm{~nm}(40 \mathrm{~nm}$ to the red of rhodamine 110). Its maximum emission at $628 \mathrm{~nm}$ displays a reasonable quantum yield of $19 \%$ and is red-shifted nearly $100 \mathrm{~nm}$ as compared to rhodamine 110 . The corresponding bis-boronic acid $\mathbf{2}$ is further red-shifted with maximum absorption and emission at 560 and $638 \mathrm{~nm}$, respectively. Emission is slightly quenched through photoinduced electron transfer (PET) in the boron-nitrogen system as evidenced by the lower quantum yield. It is interesting to note that the quenching for the original RhoBo and the fully annulated bis-boronic acid $\mathbf{4}$ discussed below is much greater than the asymmetric bisboronic acid 2. Other boronic acid-based saccharide sensors with a high degree PET have also been reported [18].

The maximum absorption of napthorhodamine 3 is further shifted to $578 \mathrm{~nm}$ with emission wavelength and quantum yield $(668 \mathrm{~nm}, 10 \%)$ comparable to commercially available naphthofluorescein. The corresponding bis-boronic acid $\mathbf{4}$ is further red-shifted with maximum absorption and emission at 628 and $692 \mathrm{~nm}$, respectively. Although it displays a reasonably strong blue/green color, its fluorescence is nearly completely quenched, allowing for a potential turn-on type sensor. Like the other compounds, its emission is slightly redder and its quantum yield is slightly higher in DMSO buffer 1:1. However, like its corresponding rhodamine precursor $\mathbf{3}$, it exists primarily in the closed and colorless lactone form in this solvent.

\section{SENSING OF SACCHARIDES}

In this exploratory work, we report our initial investigation into the responses of the two new rhodamine bis-boronic acid scaffolds toward representative sugars. More detailed investigations into the binding stochiometries and dissociation constants are ongoing. Responses of the boronic acid probes were monitored over a wide range of glucose, ribose, and fructose concentrations in various solvents. Solvents including $\mathrm{MeCN}, \mathrm{MeOH}, \mathrm{EtOH}, \mathrm{DMSO}$, and buffer were initially screened for sugar sensing. Probes were partially soluble in $\mathrm{MeCN}$ and buffer, and soluble in $\mathrm{MeOH}$, EtOH, and DMSO. Based on these screenings and our previous observations of reversed selectivity [9], DMSO mixtures were chosen for further studies. Owing to the solvent-dependent lactone ring opening-closing equilibrium (Scheme 3), these type of probes exhibit; a DMSO titration was carried out, in order to determine the range of possible conditions for sugar sensing. As shown in Fig. 8, at lower DMSO concentration, rhodamine precursors as well as the bis-boronic acids exist at least to some extent as the colored carboxylate species. As the DMSO concentration increases, the lactone form predominates (low absorbance values) for all but bis-boronic acid $\mathbf{2}$. For this case, the carboxylate form predominates over this DMSO concentration range. At DMSO concentrations of 60-90\%, precipitation occurs for all cases; however, at $90 \%$ DMSO all compounds are soluble and predominantly in their colorless closed lactone forms. It is interesting to note that the boronic acid derivatives are less prone to lactone formation than their corresponding rhodamine precursors.

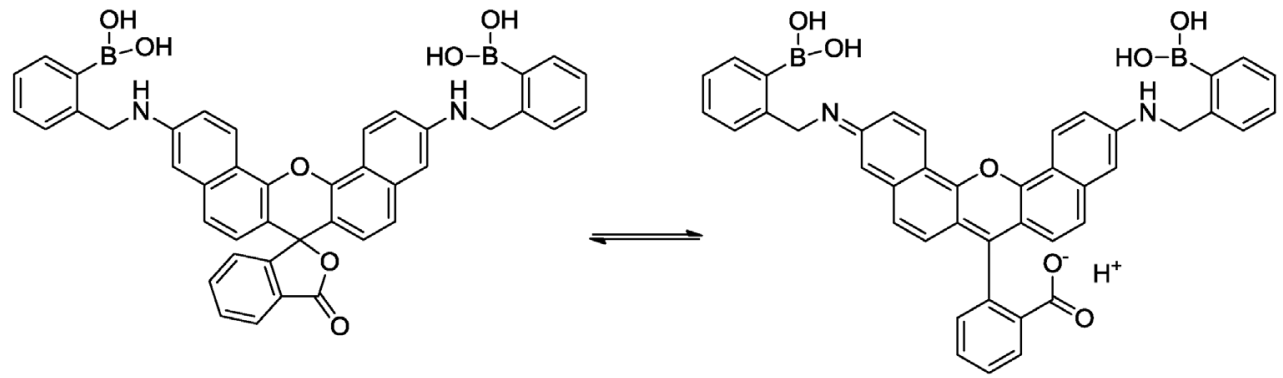

Scheme 3 Lactone ring opening-closing equilibrium in 4. 


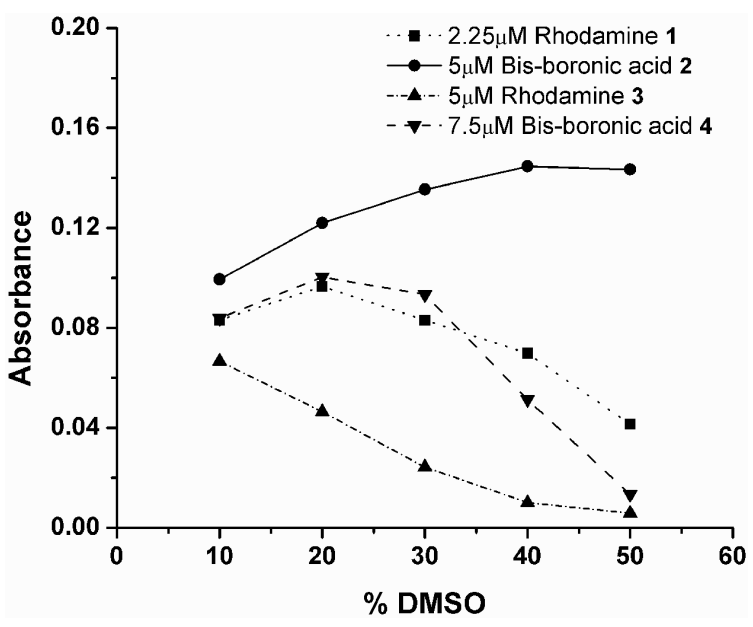

Fig. 8 DMSO titration for rhodamine precursors and rhodamine bis-boronic acids (final $\mathrm{pH} 7.4$ phosphate buffer concentration of $12.5 \mathrm{mM}$ ). Absorbance values were measured as follows: semi-naphthorhodamine 1, $532 \mathrm{~nm}$; bis-boronic acid 2, $578 \mathrm{~nm}$; naphthorhodamine 3, $578 \mathrm{~nm}$; bis-boronic acid 4, $627 \mathrm{~nm}$.

Initial screening for sensing of glucose, fructose, and ribose using these probes in mixtures DMSO:buffer 9:1 (final pH 7.4 phosphate buffer concentration of $12.5 \mathrm{mM}$ ) used in our previous work, showed that no changes in either absorbance or fluorescence were observable. Incubation either at room temperature or $37^{\circ} \mathrm{C}$ for up to $24 \mathrm{~h}$ gave similar results. It was hoped that binding of different sugars would affect the lactone ring opening-closing equilibria to differing degrees, thus providing additional selectivity; however, it appears that sugar binding did not sufficiently alter the lactone equlibria in this solvent. We believe this concept will prove useful upon further investigation, possibly in other solvent systems, as sugar binding was found to influence lactone formation for compound $\mathbf{4}$ in DMSO-buffer $1: 1$ (vide infra).

The spectral behavior of both compounds $\mathbf{2}$ and $\mathbf{4}$ in the presence of saccharides was further investigated in both 1:1 and 1:9 DMSO-buffer (final $\mathrm{pH} 7.4$ phosphate buffer concentration of $12.5 \mathrm{mM}$ ) solutions. Both bis-boronic acids responded to binding of sugars through a red shift in their emission and the expected increase in fluorescence intensity.

Figure 9 shows the response of compound 2 to fructose, ribose, and glucose under the two solvent conditions mentioned above. In the 1:9 DMSO:buffer system this asymmetric rhodamine bisboronic acid responded more strongly to fructose (Figs. 9a,b). An increase in fluorescence intensity was observed for fructose and ribose at the lowest concentration investigated in this exploratory work. At high sugar concentrations the response for all three sugars converged. A near 2-fold increase in absorbance resulted in a greater than 5-fold increase in fluorescence for all sugars. The solvent system was found to have a large effect on the response. Bis-boronic acid $\mathbf{2}$ responded most strongly to ribose in the 1:1 DMSO buffer system (Figs. 9c,d). An approximately 1.5-fold increase in both absorbance and fluorescence was observed over the entire concentration range investigated. Binding of all three sugars occurred at lower concentrations as compared to the 1:9 DMSO:buffer system; with the response of both ribose and fructose having already plateaued at $10 \mathrm{mM}$, the lowest concentration investigated. It is interesting to note that unlike the 1:9 solvent system, there are significant spectral differences in the responses toward different sugars (Fig. 9c compared to Fig 9a). Wavelength differences were also observed in the response of RhoBo when the DMSO ratio was high [8]. 
a)

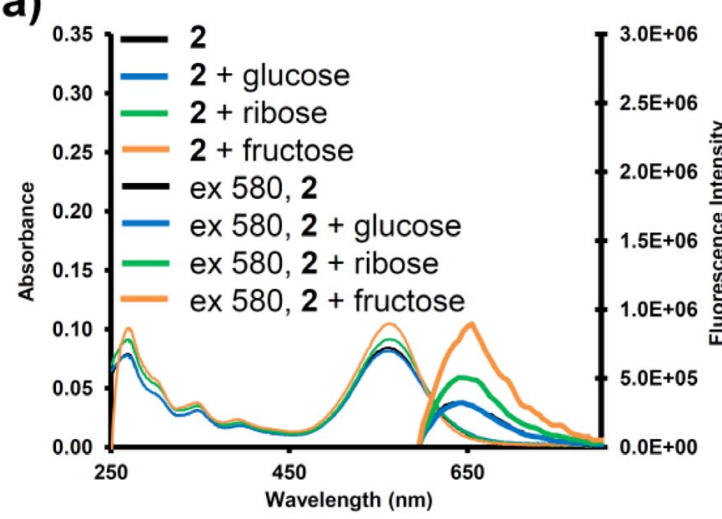

c)

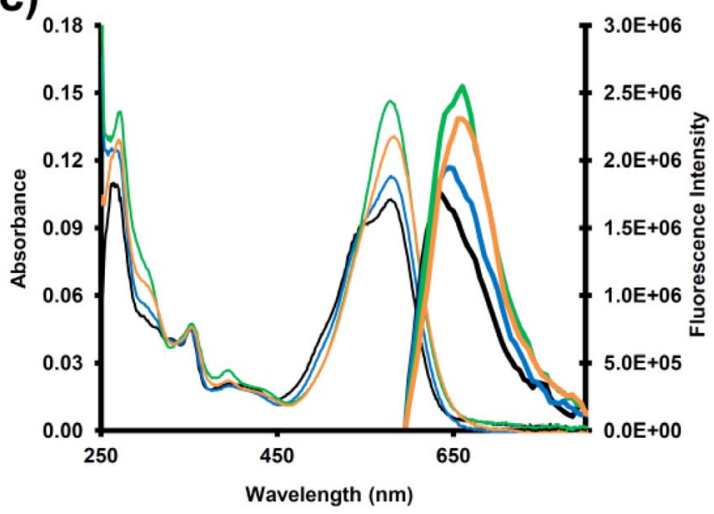

b)

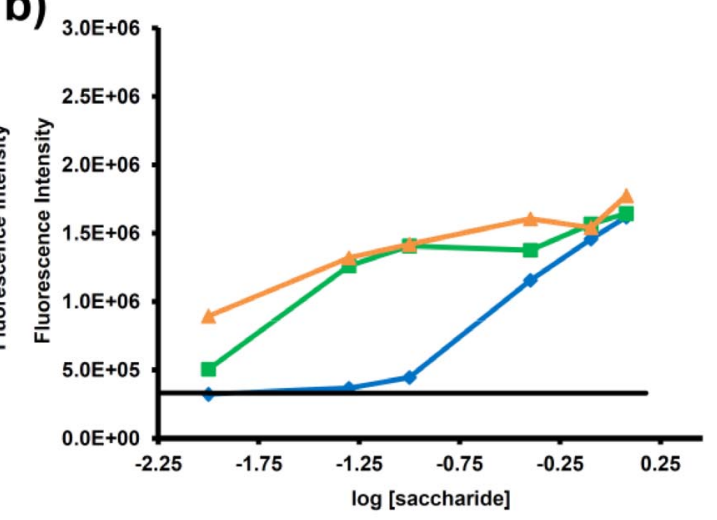

d)

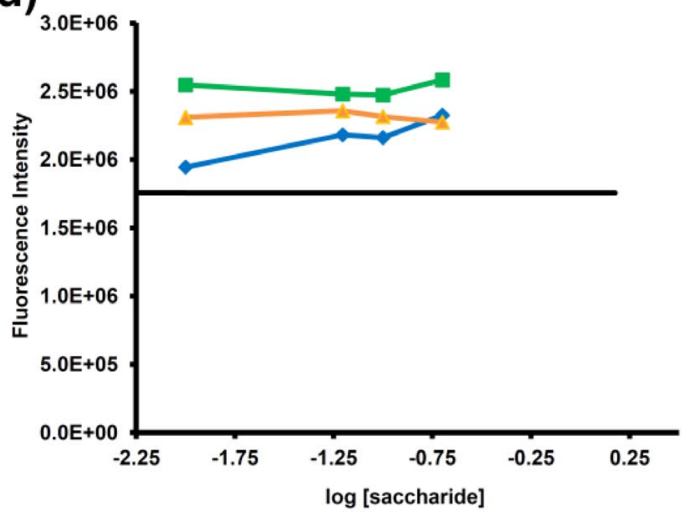

Fig. 9 Bis-boronic acid 2 in response to various saccharides. (a) Absorption and emission spectra of $2(3.75 \mu \mathrm{M})$ in response to $10 \mathrm{mM}$ sugars in DMSO:buffer 1:9. (b) Fluorescence emission (ex $580 \mathrm{~nm} / \mathrm{em} 660 \mathrm{~nm}$ ) as a function of sugar concentration in DMSO:buffer 1:9. (c) Absorption and emission spectra of $2(3.75 \mu \mathrm{M})$ in response to $10 \mathrm{mM}$ sugars in DMSO:buffer 1:1. (d) Fluorescence emission (ex $580 \mathrm{~nm} / \mathrm{em} 640 \mathrm{~nm}$ ) as a function of sugar concentration in DMSO:buffer 1:1. Final pH 7.4 phosphate buffer concentration was $12.5 \mathrm{mM}$. Horizontal lines in (b) and (d) represent fluorescence of $\mathbf{2}$ in the absence of analyte.

There were significant differences between the responses of asymmetric bis-boronic acid 2 and symmetric bis-boronic acid $\mathbf{4}$. Figure 10 shows the response of compound $\mathbf{4}$ to fructose, ribose, and glucose in both 1:9 and 1:1 DMSO:buffer systems. Of the three sugars screened, bis-boronic acid 4 responded almost exclusively to fructose at concentrations below $100 \mathrm{mM}$ in the 1:9 DMSO-buffer system (Figs. 10a,b). At the highest concentration of fructose investigated, a less than 3-fold increase in absorbance at $630 \mathrm{~nm}$ resulted in a greater than 140-fold turn-on response of fluorescence emission at $710 \mathrm{~nm}$ upon excitation at $630 \mathrm{~nm}$. No spectral shifts were observed in response to any of the sugars. It is possible that the increase in absorbance is at least partially the result of lactone opening upon sugar binding. The increase in fluorescence is largely the result of near complete disruption of the PET quenching in the boron-nitrogen system of the free rhodamine bis-boronic acid. It is estimated that the quantum yield of $\mathbf{4}$ after binding approaches $20 \%$ or more (140-fold fluorescence increase divided by 3 -fold absorbance increase multiplied by the quantum yield of the free $\mathbf{4}=0.186$ ) which is greater than the quantum yield of precursor 3. Secondary interactions and additional rigidification of the chromophore upon binding could be responsible for this further enhancement of emission. Again, the solvent system was found to have a major effect. Affinity for ribose was greatly increased, approaching the response observed for fructose at the lowest concentration investigated $(10 \mathrm{mM})$ upon changing the sol- 
a)

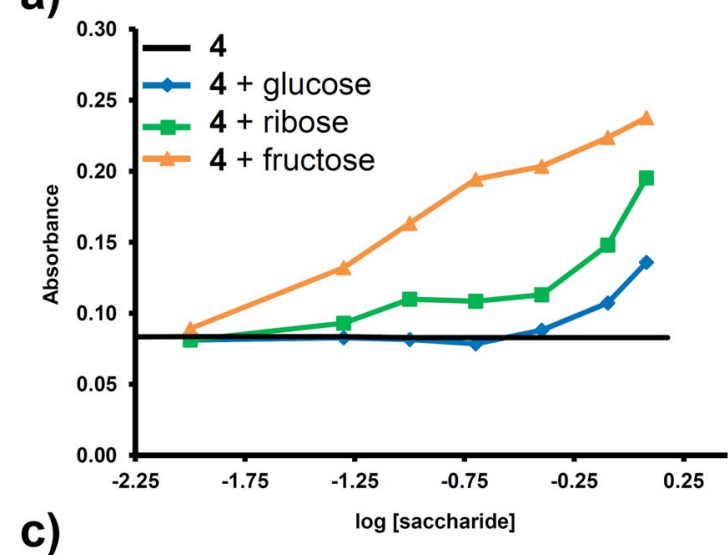

c)

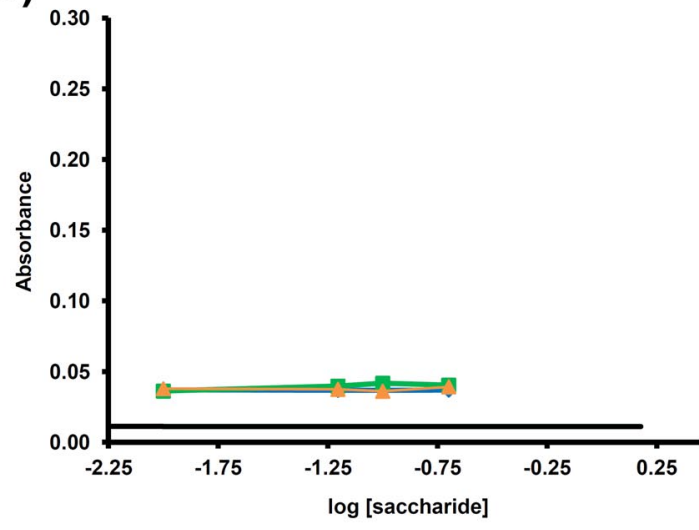

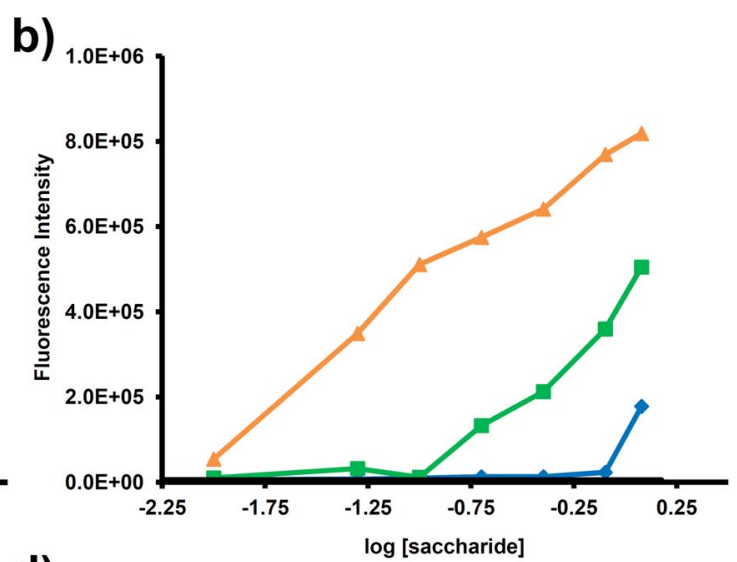

d)

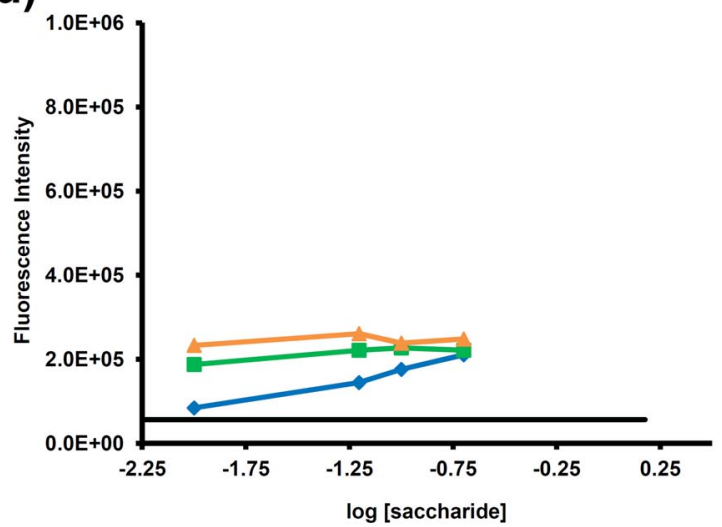

Fig. 10 Bis-boronic acid 4 in response to various saccharides. (a) Absorption (630 nm) and (b) emission (ex 630 $\mathrm{nm} / \mathrm{em} 690 \mathrm{~nm})$ of $4(7.5 \mu \mathrm{M})$ as a function of sugar concentration in DMSO:buffer 1:9. (c) Absorption (640 nm) and (d) emission (ex 640/em $700 \mathrm{~nm}$ ) of $\mathbf{4}(7.5 \mu \mathrm{M})$ as a function of sugar concentration in DMSO:buffer 1:1. Final $\mathrm{pH} 7.4$ phosphate buffer concentration was $12.5 \mathrm{mM}$. Horizontal lines represent absorbance and fluorescence of 4 in the absence of analyte.

vent system to 1:1 DMSO-buffer. Binding of all three sugars at lower concentrations (Figs. 10c,d) was found to increase and the response of all three sugars converged to nearly a 5-fold increase in emission at $720 \mathrm{~nm}$ upon excitation at $640 \mathrm{~nm}$. It is interesting to note that free bis-boronic acid 4 in 1:1 DMSObuffer is colorless, but binding of sugars promotes opening of the lactone leading to a green/blue color.

\section{RATIONALIZATION OF SELECTIVITY TRENDS}

When the solvent system is mostly aqueous (1:9 DMSO:buffer), solvation by water inhibits intramolecular interactions by salt bridges, allowing the sugar boronates complexes in $\mathbf{2}$ to adopt practically any possible conformation reaching the carboxyl group without problem, especially for the side where the rhodamine system ring is not extended. For the relatively less aqueous system (1:1 DMSO:buffer), the selectivity turns slightly toward ribose due to the enhancement of intramolecular binding interactions between the bound sugar and dye [9]. Figure 11 shows a model of ribose bis-boronate of 2 describing the electrostatic interactions within the N-H-O-B atoms in a 1:1 DMSO:buffer solution. 


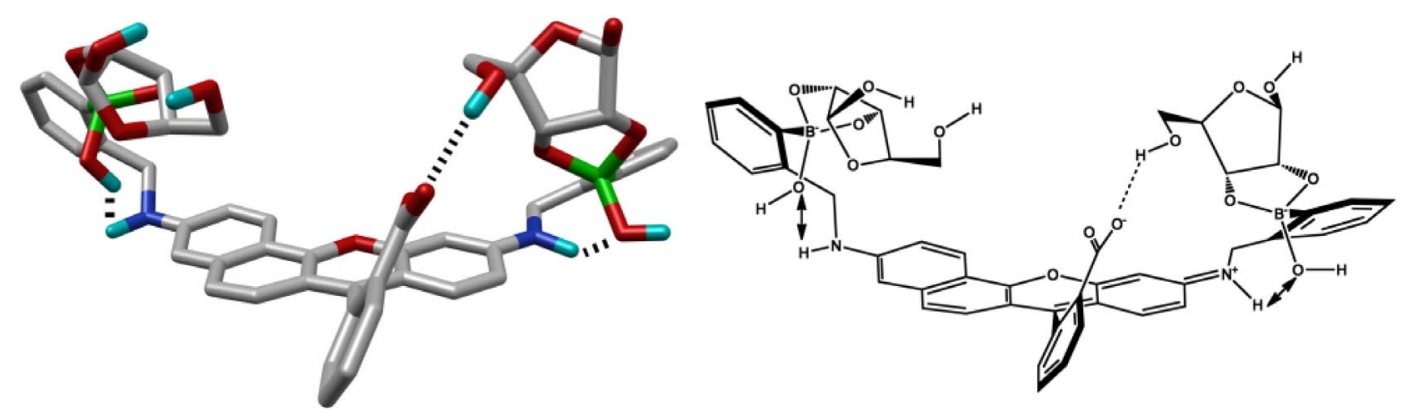

Fig. 11 Energy-minimized structure of the ribose bis-boronate of 2. In a 1:1 DMSO:buffer solution, electrostatic attraction between $\mathrm{N}-\mathrm{H}-\mathrm{O}-\mathrm{B}$ atoms restricts rotation of the $\mathrm{C}-\mathrm{B}$ bond resulting in selectivity for the ribose complex. Only one of the boronates can reach the carboxylate.

Compound 4 has both boronic acid groups far from each other and from the carboxylate compared to 2. In the 1:9 DMSO:buffer solvent system the selectivity follows the normal behavior (fructose $>$ ribose $>$ glucose). When the ratio DMSO:buffer is 1:9, the intramolecular electrostatic interactions are practically nonexistent, allowing more freedom to adopt many possible conformations, and if saccharide bis-boronates are formed, the interactions between them can make the planar chromophore to bend slightly to allow interactions with the carboxylate. Intramolecular hydrogen bond interactions between two fructose bis-boronates have been reported by the Duggan group [20]. For the system with DMSO:buffer 1:1 ratio, the electrostatic interactions are very weak, but strong enough to restrict the molecule from adopting many possible conformations. Figure 12 shows a model of a bis-boronate complex of compound $\mathbf{4}$ with two molecules of fructose.

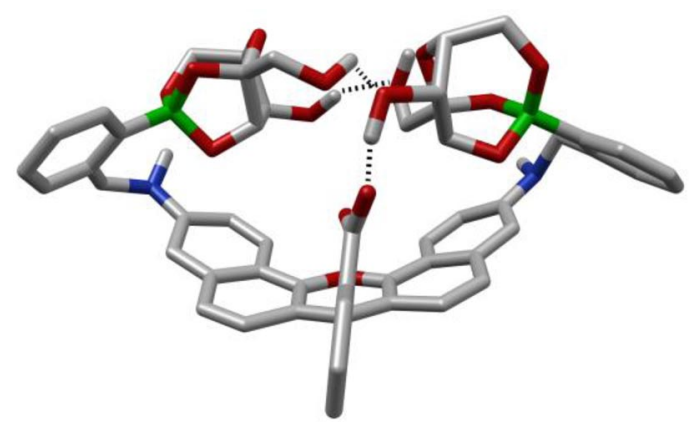

Fig. 12 Energy-minimized structure of the fructose bis-boronate complex of $\mathbf{4}$ and two molecules of fructose.

\section{CONCLUSION}

Long-wavelength rhodamine analogs and their boronic acid derivatives were synthesized and their fundamental properties evaluated. As expected, annulation led to increased absorption and emission wavelengths for both rhodamine precursors as compared to rhodamine 110. The corresponding bis-boronic acid derivatives were further red-shifted as compared to their rhodamine precursors. In the absence of sugars, the boronic acids were quenched through a PET mechanism. Bathochromic shifts and increased quantum yields were observed for both asymmetric boronic acid $\mathbf{2}$ and symmetric boronic acid $\mathbf{4}$ upon sugar binding. Both compounds exhibited the conventional selectivity trends (fructose $>$ ribose $>$ glucose) in the 1:9 DMSO:buffer system, but bis-boronic acid $\mathbf{4}$ is particularly attractive as it responded exclusively to fructose through a clear to blue/green color change with corresponding turn on NIR fluo- 
rescence enhancement of up to 140-fold and no interference from other sugars at concentrations below $100 \mathrm{mM}$. Importantly, the solvent system was found to have a large effect on the response and selectively of these compounds toward the different sugars investigated. Upon changing the solvent system to 1:1 DMSO-buffer, the affinity of symmetric $\mathbf{4}$ for ribose was greatly increased, approaching the response observed for fructose at relatively low concentrations. In this more organic solvent system, the asymmetric boronic acid $\mathbf{2}$ reversed its selectivity and responded most strongly to ribose. In this solvent system, electrostatic interactions are strong enough to restrict the molecule from adopting many possible conformations. These results combined with currently ongoing investigations into the binding stoichiometries and dissociation constants of the various systems are guiding the design and optimization of fluorogenic NIR-active rhodamines and rhodols with varying geometry and functionalization for sensing and imaging applications in our lab.

\section{ACKNOWLEDGMENTS}

The authors gratefully acknowledge the NIH for support of this work via grant RO1 EB002044.

\section{REFERENCES}

1. T. S. Fabre, W. D. Treleaven, T. D. McCarley, C. L. Newton, R. M. Landry, M. C. Saraiva, R. M. Strongin. J. Org. Chem. 63, 3522 (1998).

2. M. W. Read, J. O. Escobedo, D. M. Willis, P. A. Beck, R. M. Strongin. Org. Lett. 2, 3201 (2000).

3. (a) P. T. Lewis, C. J. Davis, M. C. Saraiva, W. D. Treleaven, T. D. McCarley, R. M. Strongin. J. Org. Chem. 62, 6110 (1997); (b) P. T. Lewis, R. M. Strongin. J. Org. Chem. 63, 6065 (1998).

4. K. K. Kim, J. O. Escobedo, N. N. St Luce, O. Rusin, D. Wong, R. M. Strongin. Org. Lett. 5, 5007 (2003).

5. C. J. Davis, P. T. Lewis, M. E. McCarroll, M. W. Read, R. Cueto, R. M. Strongin. Org. Lett. 1, 331 (1999).

6. M. He, R. J. Johnson, J. O. Escobedo, P. A. Beck, K. K. Kim, N. N. St Luce, C. J. Davis, P. T. Lewis, F. R. Fronczek, B. J. Melancon, A. A. Mrse, W. D. Treleaven, R. M. Strongin. J. Am. Chem. Soc. 124, 5000 (2002).

7. (a) T. D. James, K. Sandanayake, S. Shinkai. Angew. Chem., Int. Ed. 35, 1910 (1996); (b) K. Sandanayake, T. D. James, S. Shinkai. Pure Appl. Chem. 68, 1207 (1996).

8. S. Lim, J. O. Escobedo, M. Lowry, R. M. Strongin. Chem. Commun. 47, 8295 (2011).

9. S. Jiang, J. O. Escobedo, K. K. Kim, O. Alptürk, G. K. Samoei, S. O. Fakayode, I. M. Warner, O. Rusin, R. M. Strongin. J. Am. Chem. Soc. 128, 12221 (2006).

10. G. Springsteen, B. H. Wang. Tetrahedron 58, 5291 (2002).

11. (a) L. Zhu, S. H. Shabbir, M. Gray, V. M. Lynch, S. Sorey, E. V. Anslyn. J. Am. Chem. Soc. 128, 1222 (2006); (b) B. E. Collins, S. Sorey, A. E. Hargrove, S. H. Shabbir, V. M. Lynch, E. V. Anslyn. J. Org. Chem. 74, 4055 (2009).

12. T. L. Halo, J. Appelbaum, E. M. Hobert, D. M. Balkin, A. Schepartz. J. Am. Chem. Soc. 131, 438 (2008).

13. S. Lim, M. Lowry, R. M. Strongin. Aust. J. Chem. 64, 1470 (2011).

14. J. E. Whitaker, R. P. Haugland, F. G. Prendergast. Anal. Biochem. 194, 330 (1991).

15. Y. J. Yang, M. Lowry, X. Y. Xu, J. O. Escobedo, M. Sibrian-Vazquez, L. Wong, C. M. Schowalter, T. J. Jensen, F. R. Fronczek, I. M. Warner, R. M. Strongin. Proc. Natl. Acad. Sci. USA 105, 8829 (2008).

16. L. G. Lee, G. M. Berry, C.-H. Chen. Cytometry 10, 151 (1989).

17. K. Furukawa, H. Abe, J. Wang, M. Uda, H. Koshino, S. Tsuneda, Y. Ito. Org. Biomol. Chem. 7, 671 (2009). 
18. (a) T. D. James, K. Sandanayake, S. Shinkai. J. Chem. Soc., Chem. Commun. 477 (1994); (b) T. D. James, K. Sandanayake, R. Iguchi, S. Shinkai. J. Am. Chem. Soc. 117, 8982 (1995).

19. S. P. Leytus, L. L. Melhado, W. F. Mangel. Biochem. J. 209, 299 (1983).

20. S. P. Draffin, P. J. Duggan, S. A. M. Duggan. Org. Lett. 3, 917 (2001). 
Copyright of Pure \& Applied Chemistry is the property of International Union of Pure \& Applied Chemistry (IUPAC) and its content may not be copied or emailed to multiple sites or posted to a listserv without the copyright holder's express written permission. However, users may print, download, or email articles for individual use. 